Yang Woo Kim is a senior economist for the Bank of Korea. From August 1995 to J uly 1996, he was a visiting scholar in the research department of the Federal Reserve Bank of St. Louis. Nick Meggos and Kelly Morris provided research assistance. The views expressed are those of the author and do not necessarily reflect official positions of the FRB of St. Louis, the Federal Reserve System, the Board of Governors, and the Bank of Korea. The author is grateful to Mike Dueker, Bill Gavin, Barry Jones, and Travis Nesmith for helpful comments and suggestions.

\title{
Are Prices Countercyclical? Evidence From East Asian Countries
}

\section{Yang Woo Kim}

The cyclicality of prices has been in debate recently. One of the key stylized facts that has served as a cornerstone for traditional business cycle models is the procyclical behavior of prices. Recent research has questioned the empirical basis for this stylized fact. Using quarterly U.S. data, Kydland and Prescott (1990) report that cyclical components of U.S. prices and output are correlated negatively in the post-Korean War period. They cite this result as evidence against the conventional understanding that prices are procyclical.

Cooley and Ohanian (1991) confirm the negative correlation in the post-W WII period and also find that if the sample is extended into the nineteenth century, the data are not at all suggestive of procyclical prices, with the important exception of the inter-war period. They interpret their findings of countercyclical prices as being inconsistent with the predictions of demanddriven models and instead supportive of real business-cycle models.

The work of other researchers, such as Backus and Kehoe (1992) and Smith (1992), complements these studies by examining cross-country evidence. For example, Smith finds that, for ten countries, fluctuations in the price level generally are procyclical from the late nineteenth century until WWII, with the exception of a period around WWI. Pricelevel movements are countercyclical in the
post-Depression period, however, with the possible exception of a period in the 1950 s or 1960s. These facts suggest that procyclical price movement is not a stable feature across many business cycles.

Chadha and Prasad $(1993,1994)$ show the importance of making a clear distinction between inflation and the cyclical component of the price level in reports and interpretations of stylized facts regarding business cycles. They find that, in postwar quarterly data for the United States, as well as for the rest of the G-7 countries, the cyclical components of the price-level and output series are negatively correlated. The inflation rate, however, is generally correlated positively with various measures of the cyclical component of output, suggesting that demand-driven models of the business cycle are not necessarily falsified by the countercyclical behavior of the price level.

Similarly, Hall (1995) argues that the conclusions on the sources of the business cycle of Cooley and Ohanian, and Kydland and Prescott are flawed. He shows that a negative correlation between detrended output and detrended prices is predicted by the natural-rate nominal-demand shock model, under reasonable assumptions. In other words, he shows that the naturalrate model suggests that procyclical prices imply a positive correlation between the change in inflation and detrended output. Judd and Trehan (1995) argue that the use of cross-correlation coefficients as indicators for evaluating the empirical relevance of demand-oriented versus supply-oriented macroeconomic theories is problematic in principle. Using two econometric models, they show that correlation coefficients for prices and output could easily be negative even if demand shocks were the primary source of cyclical fluctuations and prices were procyclical. Gavin and Kydland (1995) show that alternative money supply rules can change the 
cyclical nature of prices in a flexible-price economy.

The purpose of this paper is to document the empirical evidence on the cyclical behavior of prices and inflation in two rapidly growing developing countries-Korea and Taiwan. I use the methodology of Chadha and Prasad (1994) to see if results from advanced countries are robust when compared to the results from these developing countries, whose business cycles may have different characteristics. In addition to the usual techniques for detrending-linear detrending, first differencing, and Hodrick-Prescott (HP) filtering - two more techniques are utilized. That is, the Zivot-Andrews' (1992) procedure of a unit root test with a structural break at an unknown point in time is used to enable researchers to consider possibilities of a segmented trend of the data. Also, a smooth trend based on the phase average trend (PAT) technique (Klein and Moore, 1985; Zarnowitz, 1992) that is popular in growth-cycle literature is estimated and used in detrending the time series to confirm the robustness of the empirical findings.

The next section of this paper discusses the strategy of the trend-cycle decomposition and related issues. The third and fourth sections present empirical correlations of prices and inflation with the cyclical component of output in Korea and Taiwan. The final section summarizes the main results and implications.

\section{Trend-Cycle Decomposition}

To examine the co-movement of macroeconomic variables over the business cycle, it is necessary to use a procedure based on an appropriate measure of the cyclical component of the series. It has been well documented that macroeconomic variables are nonstationary in general. The characterization of the form of the nonstationarity is very important, since it will affect the nature of the stationary component as well as the permanent component of a time series. ${ }^{1}$ However, there is no consensus on the correct trend-cycle decomposition method.
There are several widely used transformations, including deterministic linear detrending, first differencing, and other types of stochastic detrending such as Hodrick and Prescott (1981) filtering. Since each technique suggested has its own limitations, depending on the nature of the input series and the issues addressed, it is likely that different detrending methods will be useful in different applications.

To get around problems associated with particular detrending methods, some researchers adopt an eclectic strategy in detrending a time series-i.e., instead of using a particular technique for detrending, they try various detrending methods and evaluate the robustness of the results across techniques. Cooley and Ohanian (1991) and Smith (1992) use three filters in calculating the cross-correlations of price and output: linear, first-difference, and HP. Chadha and Prasad $(1993,1994)$ try a segmented trend based on Perron (1989) and a stochastic detrending method used by Beveridge and Nelson (1981) and Blanchard and Quah (1989) as alternatives.

In this study, I basically follow Chadha and Prasad's strategy in using a variety of detrending procedures. I use the three filters-linear, first-difference, and $\mathrm{HP}$ - as well as two others. Instead of BeveridgeNelson detrending (1981) or Blanchard and Quah's method (1989), I investigate the nature of the nonstationarity of the time series more thoroughly by applying Zivot and Andrews' unit root test (1992) under the alternative of trend stationarity with a break at an unknown point in time. A break point identified by this procedure is then used for setting up a segmented linear trend. I also calculate a fifth decomposition with the Growth Cycle program based on the PAT technique.

A deterministic linear trend is free of any cyclical or any other short-run movements; as a result, it guarantees a clear decomposition of the series into a trend and cyclical component. But it is not likely that a deterministic trend, or trendstationary process, would represent the 
real world across periods of dramatic changes such as the Great Crash of 1929, or World War II or periods of structural changes in developing economies. Another detrending method, first differencing, is included for completeness, but it is probably not appropriate for studying the cyclical nature of prices, since it removes information at cyclical frequencies. Most real business-cycle researchers have extensively used the Hodrick and Prescott filter (1981). Kydland and Prescott (1982) choose it because it focuses on fluctuations at cyclical frequencies. This technique, however, has been criticized by several researchers (King and Rebelo, 1993; Cogley and Nason, 1995; Harvey and Jaeger, 1993; Gregory and Smith, 1995), because mechanical detrending based on the HP filter could lead investigators to report spurious cyclical behavior. The last two methods I use- the segmented linear method and the PAT technique-have not been widely used in the business-cycle literature. Therefore, I include a detailed discussion of these two methods before analyzing the cyclical behavior of prices in Korea and Taiwan.

\section{The Segmented Linear Method}

Since N elson and Plosser (1982), the popular view has been that most macroeconomic variables have a unit root- that is, they follow stochastic trends. Recently, evidence against this unit root hypothesis has been presented by various authors. Perron (1989) shows that, once a break in the trend is allowed in the data, the unit root hypothesis can be rejected in favor of the alternative hypothesis of stationarity around a deterministic trend that has an exogenous break at either the Great Crash or the 1973 oil shock. This situation is true for postwar quarterly U.S. real GNP as well as for eight of the el even macroeconomic time series $\mathrm{N}$ elson and Plosser examined. Perron's results are criticized and further elaborated by several researchers, on the ground that his choice of a break point in the trend is ad hoc and hence cannot circumvent the problem of data-mining (Christiano, 1992; Zivot and Andrews,
1992). By treating the breakpoint as endogenous, they find less evidence against the unit root hypothesis than Perron finds for many of the data series but stronger evidence against it for several of the series. Similarly, Banerjee, Lumsdaine, and Stock (1992) examine the unit root hypothesis on postwar real output of G-7 countries using tests based on asymptotic distribution theory, which treats break dates as unknown a priori, and they find that the null hypothesis of a unit root can be rejected only for Japan. Serletis (1994), who bases his research on the Zivot and Andrews' technique (1992), finds that the unit root model can be rejected for real per capita output series in eight out of ten countries over the period of 1870 to 1985 , if a one-time break is allowed at an unknown point in time. Using the same technique, Alba and Papell (1995) examine unit roots in aggregate and real per capita GDP for nine newly industrializing countries (NIC) and newly exporting (NEC) countries in east and southeast Asia. In 15 out of 18 cases, they reject the unit root hypothesis in favor of the theory of trend stationarity with a break. Overall, the results from these studies suggest that the international evidence of the unit root model is mixed as far as output is concerned, either real GDP or per capita GDP; the outcome depends on how certain big shocks (such as the Great Crash of 1929) are treated.

Here I use Zivot-Andrews' variant of the sequential Dickey-Fuller test of a unit root, which can be represented by the following equation:

$$
\begin{aligned}
& \Delta \mathrm{Y}_{\mathrm{t}}=\mu+\theta D \mathrm{DU}_{\mathrm{t}}+\beta \mathrm{t}+\gamma \mathrm{DT}_{\mathrm{t}} \\
& +\alpha \mathrm{Y}_{\mathrm{t}-1}+\sum \mathrm{c}_{\mathrm{i}} \Delta\left(\mathrm{Y}_{\mathrm{t}-\mathrm{j}}\right)+\mathrm{e}_{\mathrm{t}}
\end{aligned}
$$

where $D U=1$ and DT $=t-T B$ if $t>T B$ and 0 otherwise. This tests the null hypothesis of a unit root against the alternative hypothesis of a trend stationarity with a one-time break (TB) in the intercept and slope of the trend function at an unknown point in time. For this, different regressions are run for $T B=2,3, \ldots, T-1$, where $T$ is the number of observations adjusted 


\section{Table 1}

\section{Test for Unit Root: Zivot-Andrews' Procedure 1992}

\begin{tabular}{|c|c|c|c|c|c|c|}
\hline Variables & Sample & Break Point & $\alpha$ & $t-v a l u e$ & Model & $\mathrm{k}$ \\
\hline \multicolumn{7}{|c|}{ Korea } \\
\hline GNP & $1970.10-95.20$ & 1979.20 & -0.25 & -4.6 & A & 2 \\
\hline Deflator & $1970.10-95.2 Q$ & 1979.40 & -0.22 & $-5.41^{*}$ & C & 5 \\
\hline CPI & $1970.10-95.20$ & 1979.30 & -0.15 & $-6.20 *$ & C & 12 \\
\hline \multicolumn{7}{|c|}{ Taiw an } \\
\hline GDP & 1961.1Q-95.3Q & 1977.40 & -0.23 & -4.21 & B & 10 \\
\hline Deflator & $1961.1 Q-94.40$ & 1973.10 & -0.06 & -4.21 & A & 4 \\
\hline CPI & 1959.1Q-95.4Q & 1982.20 & -0.05 & -3.4 & B & 6 \\
\hline
\end{tabular}

for lost data caused by differencing and lag length $\mathrm{k}$. The lag length is selected according to the procedure suggested by Perron (1989). Working backwards from $k=12$, I choose the first value of $k$ such that the t-statistic on the last lag in the autoregression is greater than 1.6 in absolute value and the t-statistic on the last lag in higher order autoregression is less than 1.6.

A break point is chosen that gives the The results of the standard augmented Dickey-Fuller unit test suggest that output and price series in both countries have a unit root if no break in the trend is taken into account.

3 The results for the unit root test for the output series are slightly different, in terms of either model chosen or the break point, compared to Alba and Papell (1995). This difference in outcome seems to stem from differences in the data sets. Alba and Papell use annual data collected and adjusted by Summers and Hester (1953- 1988 for Korea, 1950 - 1988 for Taiwan), while I use quarterly data pulled directly out of the IFS from IMF and DRI. Part of the reason for the difference will be the length of the sample period. My data has been updated until recently and hence has a longer sample period than theirs, which ends at 1988.
Taiwan output series follows model B, in which the slope of the trend changes. In the case of prices, model $\mathrm{C}$ is chosen for both the CPI and GNP deflator in Korea, while models $A$ and $B$ are chosen for the Taiwan deflator and CPI respectively. Note that the chosen potential structural break period in the trend of each series is not the same for the two countries ${ }^{3}$ (see, also, Figures la through $1 d$ on the time paths of the Dickey-Fuller t-statistics). This difference suggests that a break-inducing exogenous event, such as the oil shock in the 1970s, may not have affected these countries at the same time, partly because of differences in government policy and different levels of development in each country. Among the six cases, the unit root hypothesis is rejected for the Korean deflator and CPI at the 5 percent level of significance. The results from Table 1 may imply that the nature of the nonstationarity of the output series is different country-by-country; therefore, care should be taken in applying a specific detrending procedure.

\section{The Phase Average Trend Technique}

Another trend-fitting measure used is the Phase Average Trend (PAT) technique, combined with the turning-point selection program, which is used in growth-cycle literature. Growth cycles are measured by calculating the observed monthly deviations from the trend. Klein and Moore (1985) have adapted the computer pro- 


\section{Figure 1}

\section{Dickey-Fuller t-statistics}

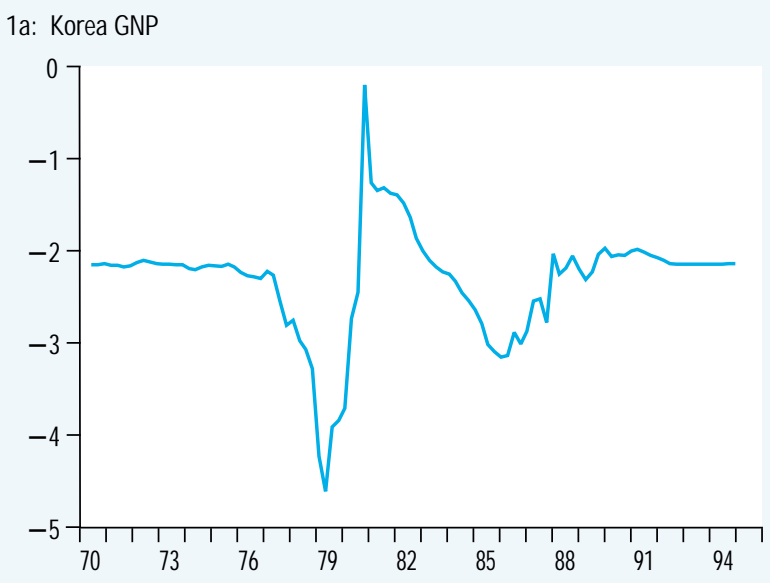

1c: Taiw an GDP

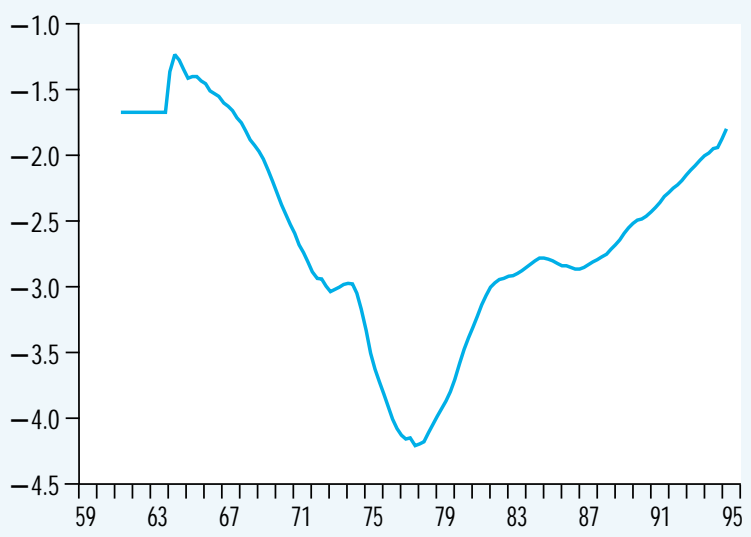

1b: Korea CPI

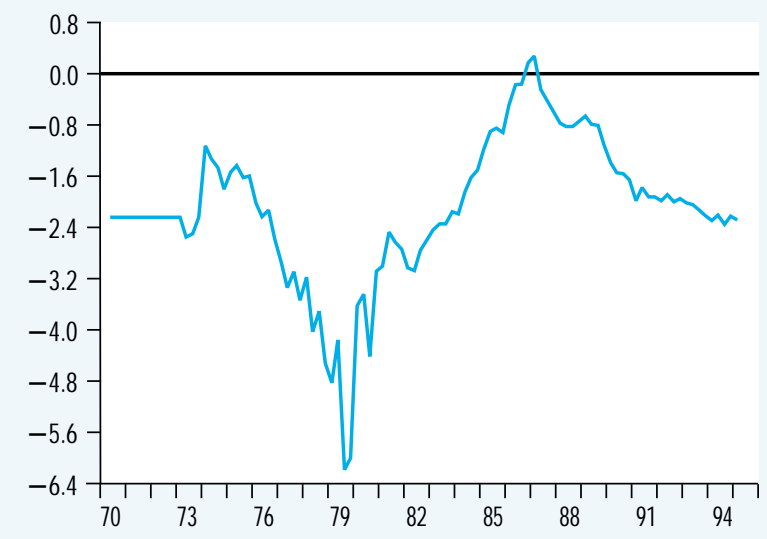

1d: Taiw an CPI

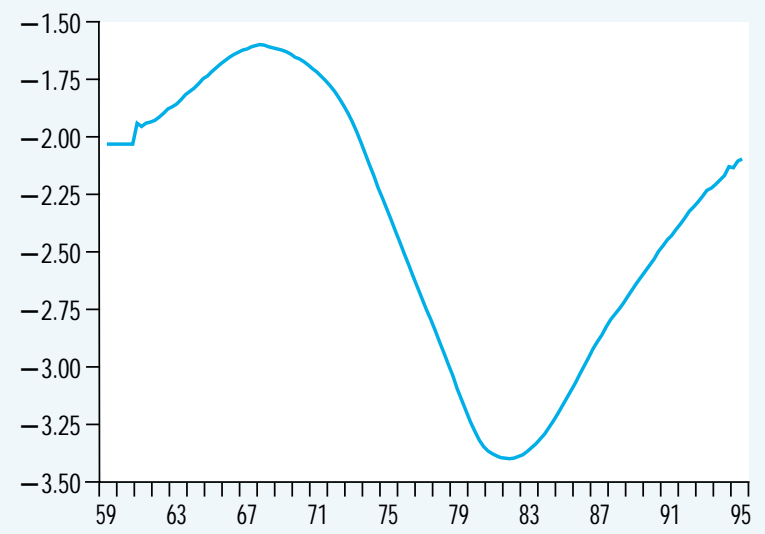

gram for dating classical cycles, originally developed by Bry and Boschan (1971), so that it can be used in producing growthcycle chronologies. The traditional way of getting a trend from the data in early business-cycle literature is to calculate the moving average of the series for a fixed period of time in the context of the beginning and end points of the data. Klein and Moore find the trend rate calculated in this way to be noticeably affected by the shorter cycles in the series. To correct for this problem, they devised the new trendfitting technique, PAT.

The PAT technique involves a trend adjustment-a moving average over the two or three phases of cycles of varying duration. For example, after the seasonally adjusted data are smoothed to produce a seventy-five-month moving average, observed deviations from this initial trend are first calculated. From this rough deviation cycle, tentative turning points (peaks and troughs) are identified and temporary phases of varying lengths are determined. Then final trend estimates are computed as a two- or three-phase moving average of the original, seasonally adjusted data, interpolating monthly between the centered values of these averages. The cyclical component of the series can be obtained by calculating the deviations of the original data from this refined and flexible nonlinear trend estimate. Klein and Moore 


\section{REVIEW}

September/ October 1996

\section{Figure 2}

\section{Detrended Output: Korea}

a.

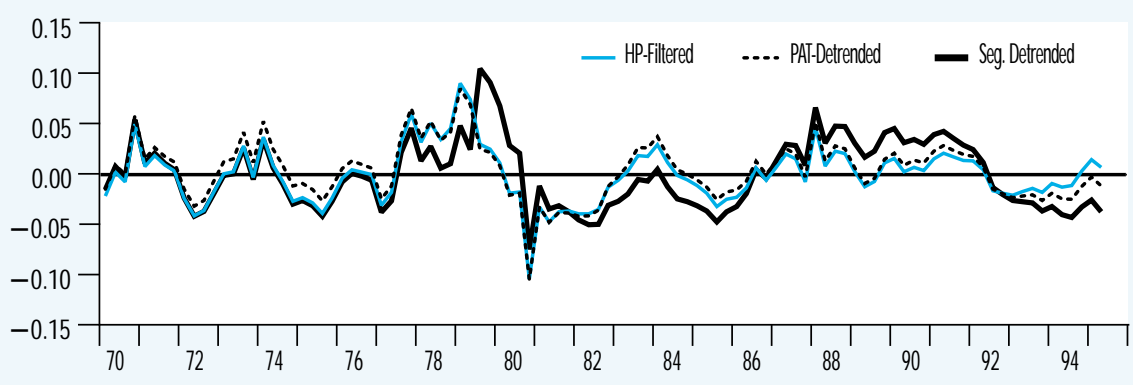

b.

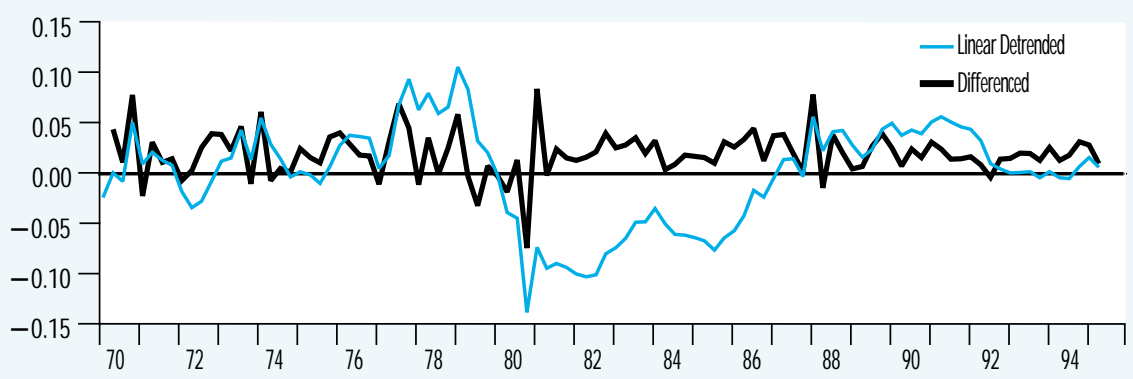

argue that the trend-fitting method will be more satisfactory than the simple moving average in separating cyclical influences from the underlying trend. As a result, they argue, the data can then identify relatively stable trend rates of growth, unassociated with the shorter cyclesa primary concern of business-cycle researchers. This procedure is applied to the Korean and Tai wan data to obtain the alternative measure of cyclical components.

\section{Comparing the Alternative \\ Measures of the Cyclical Component}

Figures $2 a$ and $2 b$ depict the five alternative measures of the cyclical component for Korean GNP. The three most similar, shown in Figure $2 \mathrm{a}$, are those derived through the HP, the PAT, and the segmented linear trend methods. For all three methods, the average frequency and amplitude of the calculated cycles appears to be roughly consistent with business cycles lasting 4 to 6 years. Figure $2 \mathrm{~b}$ includes the two extremes: The linear trend method suggests too few cycles, and the first- difference method suggests too many to be consistent with conventional ideas about the length of business cycles.

To identify the similarities of each calculated cyclical component, correlations between measures are calculated in Table 2. The lower triangle of each panel represents correlations between cyclical components of output, while the higher triangle of each panel represents correlations between cyclical components of price calculations based on the consumer price index. N ote that the correlations between the first-differenced series and those detrended by either linear trend or segmented trend are not significant. This is the expected result from Table 1, because output and prices should be modeled as having either a deterministic or a stochastic trend.

In general, the cyclical components of output and prices, when detrended by the PAT technique, are closely related with the cyclical components derived from all other methods. In particular, PAT detrended components are most strongly related with 
Table 2

\section{Correlations between Cyclical Components of Output and Prices}

KOREA

\begin{tabular}{|c|c|c|c|c|c|}
\hline Output Prices & Linear Trend & Segmented Trend & HP Filter & PAT & Difference \\
\hline Linear trend & 1 & 0.3 & 0.37 & 0.66 & 0.08 \\
\hline Segmented trend & 0.69 & 1 & 0.69 & 0.52 & -0.13 \\
\hline HP filter & 0.76 & 0.74 & 1 & 0.81 & 0.17 \\
\hline PAT & 0.76 & 0.75 & 0.97 & 1 & 0.2 \\
\hline First Difference & 0.23 & 0.18 & 0.39 & 0.4 & 1 \\
\hline \multicolumn{6}{|c|}{ TAIWAN } \\
\hline Linear trend & 1 & 0.8 & 0.45 & 0.67 & 0.1 \\
\hline Segmented trend & 0.53 & 1 & 0.52 & 0.8 & -0.01 \\
\hline HP filter & 0.49 & 0.91 & 1 & 0.9 & 0.22 \\
\hline PAT & 0.6 & 0.83 & 0.96 & 1 & 0.17 \\
\hline First Difference & 0.15 & 0.24 & 0.31 & 0.28 & 1 \\
\hline
\end{tabular}

* The lower (higher) triangle of each panel represents the correlation between cyclical components of output (prices).

HP filtered series. For example, the correlations between the two measures in Korea are, respectively, 0.97 for output and 0.81 for prices. The cyclical components calculated with the first-difference filter are least correlated with the cyclical components calculated by means of the other methods.

\section{Correlation Between Cyclical Components of Prices and Output}

In this section, price-output relationships for each country are investigated by means of various detren ded series based on the techniques discussed above. First, I detrend prices and output using a deterministic linear trend. Second, I detrend prices and output using a segmented linear trend, with a break point in either the level and/or slope of the trend, depending on which model is appropriate for each country. The periods for a structural break in the trend of output and prices are different across the countries. Third, I use the HP filter to detrend the prices and output series. Fourth, I detrend prices and output by means of the PAT technique. And finally I take first differences of both prices and output. By construction, these are interpreted as the relation between inflation and economic growth rates. As discussed above, care should be taken in interpreting these results as having cyclical implications, because first-differenced series do not generally yield the cyclical components of the original series.

Table 3 shows the cross-correlations of prices and output, to each of which the same transformation techniques are applied. For each country, two measures of price series are used. The correlations are reported up to four lags and leads, and the standard errors are computed under the null hypothesis that the true correlation coefficient is zero. The results show that the standard errors for cross correlation coefficients are very similar.

The first panel reports the correlations between prices and output series, with both series detrended using a simple linear trend. The numbers are all significantly negative for Korea. However, in the case of Taiwan the correlations are positive at all leads and lags with the deflator, and mostly positive with the CPI.

The second panel shows the result when both prices and output series are modeled as stationary around a segmented time trend, allowing for a different break in each series. The correlations in Korea are still negative, although smaller than those of the first panel. In Taiwan, however, the correlations change their signs to become negative for both the deflator and the CPI. 


\section{Table 3}

\section{Cross Correlations of Prices and Output with Same Detrending Methods for Both Series}

\begin{tabular}{|c|c|c|c|c|}
\hline Lead/ Lag & \multicolumn{2}{|c|}{ Korea } & \multicolumn{2}{|c|}{ Taiwan } \\
\hline \multirow[t]{2}{*}{ (二 denotes lag) } & Deflator & $\underline{\mathrm{CPI}}$ & Deflator & $\underline{\mathrm{CPI}}$ \\
\hline & \multicolumn{3}{|c|}{ Detrended Prices and Output (Linear Trend for Both) } & \\
\hline 4 & $-0.50 \quad(0.10)$ & $-0.59(0.10)$ & $0.12(0.09)$ & $-0.02(0.09)$ \\
\hline 3 & $-0.50 \quad(0.10)$ & $-0.61 \quad(0.10)$ & $0.15 \quad(0.09)$ & $-0.00(0.09)$ \\
\hline 2 & $-0.49 \quad(0.10)$ & $-0.61 \quad(0.10)$ & $0.19 \quad(0.09)$ & $0.02 \quad(0.09)$ \\
\hline 1 & $-0.47 \quad(0.10)$ & $-0.60 \quad(0.10)$ & $0.23 \quad(0.09)$ & $0.06 \quad(0.09)$ \\
\hline 0 & $-0.45 \quad(0.10)$ & $-0.58 \quad(0.10)$ & $0.29 \quad(0.09)$ & $0.11 \quad(0.09)$ \\
\hline-1 & $-0.41 \quad(0.10)$ & $-0.55 \quad(0.10)$ & $0.33 \quad(0.09)$ & $0.16 \quad(0.09)$ \\
\hline-2 & $-0.38 \quad(0.10)$ & $-0.51 \quad(0.10)$ & $0.38 \quad(0.09)$ & $0.21 \quad(0.09)$ \\
\hline-3 & $-0.34 \quad(0.10)$ & $-0.47 \quad(0.10)$ & $0.42 \quad(0.09)$ & $0.27 \quad(0.09)$ \\
\hline \multirow[t]{2}{*}{-4} & $-0.31 \quad(0.10)$ & $-0.42(0.10)$ & $0.45 \quad(0.09)$ & $0.32(0.09)$ \\
\hline & \multicolumn{3}{|c|}{ Detrended Prices and Output (Segmented Trend for Both) } & \\
\hline 4 & $-0.15 \quad(0.10)$ & $-0.18 \quad(0.10)$ & $-0.14(0.09)$ & $-0.53(0.09)$ \\
\hline 3 & $-0.09 \quad(0.10)$ & $-0.26 \quad(0.10)$ & $-0.20(0.09)$ & $-0.55(0.09)$ \\
\hline 2 & $-0.18 \quad(0.10)$ & $-0.34 \quad(0.10)$ & $-0.26(0.09)$ & $-0.56(0.09)$ \\
\hline 1 & $-0.19 \quad(0.10)$ & $-0.42 \quad(0.10)$ & $-0.29(0.09)$ & $-0.54(0.09)$ \\
\hline 0 & $-0.29 \quad(0.10)$ & $-0.50 \quad(0.10)$ & $-0.29(0.09)$ & $-0.49(0.09)$ \\
\hline-1 & $-0.31 \quad(0.10)$ & $-0.53 \quad(0.10)$ & $-0.29(0.09)$ & $-0.41(0.09)$ \\
\hline-2 & $-0.32 \quad(0.10)$ & $-0.43 \quad(0.10)$ & $-0.26(0.09)$ & $-0.32(0.09)$ \\
\hline-3 & $-0.22 \quad(0.10)$ & $-0.35 \quad(0.10)$ & $-0.23(0.09)$ & $-0.24(0.09)$ \\
\hline \multirow[t]{2}{*}{-4} & $-0.18 \quad(0.10)$ & $-0.21 \quad(0.10)$ & $-0.23(0.09)$ & $-0.15(0.09)$ \\
\hline & \multicolumn{3}{|c|}{ Detrended Prices and Output (HP Filter for Both) } & \\
\hline 4 & $-0.29 \quad(0.10)$ & $-0.26 \quad(0.10)$ & $-0.68(0.09)$ & $-0.59(0.09)$ \\
\hline 3 & $-0.32 \quad(0.10)$ & $-0.39 \quad(0.10)$ & $-0.76(0.09)$ & $-0.73(0.09)$ \\
\hline 2 & $-0.39 \quad(0.10)$ & $-0.51 \quad(0.10)$ & $-0.74(0.09)$ & $-0.79(0.09)$ \\
\hline 1 & $-0.40 \quad(0.10)$ & $-0.57 \quad(0.10)$ & $-0.63(0.09)$ & $-0.75(0.09)$ \\
\hline 0 & $-0.47 \quad(0.10)$ & $-0.58 \quad(0.10)$ & $-0.47(0.09)$ & $-0.63(0.09)$ \\
\hline-1 & $-0.37 \quad(0.10)$ & $-0.54 \quad(0.10)$ & $-0.27(0.09)$ & $-0.45(0.09)$ \\
\hline-2 & $-0.26 \quad(0.10)$ & $-0.48 \quad(0.10)$ & $-0.08(0.09)$ & $-0.26(0.09)$ \\
\hline-3 & $-0.15 \quad(0.10)$ & $-0.37 \quad(0.10)$ & $0.07(0.09)$ & $-0.09(0.09)$ \\
\hline-4 & $-0.07 \quad(0.10)$ & $-0.21 \quad(0.10)$ & $0.20(0.09)$ & $0.09(0.09)$ \\
\hline
\end{tabular}

The third panel shows the results for the HP-filtered prices and output. The basic picture remains the same as in the second panel, but negative associations are getting stronger in Korea (see also Figure 3 , page 78) and at the leads in Taiwan. The fourth panel shows that the correlations are generally negative for both countries when the cyclical components of price and output series are extracted by PAT tech- nique. A striking feature of this panel is that in Taiwan negative correlations stand out and are stronger than in Korea, especially at the leads.

Finally, the correlations between the first log-differenced prices and output (i.e. inflation and economic growth) are shown in the last panel. Again they are all negative in Korea except lead 1 and lag 3 in the deflator case, although they are weaker 


\section{Cross Correlations of Prices and Output with Same Detrending Methods for Both Series}

\begin{tabular}{|c|c|c|c|c|}
\hline Lead/ Lag & \multicolumn{2}{|c|}{ Korea } & \multicolumn{2}{|c|}{ Taiwan } \\
\hline \multirow[t]{2}{*}{ (- denotes lag) } & Deflator & $\underline{\mathrm{CPI}}$ & Deflator & $\underline{\mathrm{CPI}}$ \\
\hline & \multicolumn{4}{|c|}{ Detrended Prices and Output (PAT for Both) } \\
\hline 4 & $-0.14 \quad(0.10)$ & $-0.17 \quad(0.10)$ & $-0.55(0.09)$ & $-0.51(0.09)$ \\
\hline 3 & $-0.13 \quad(0.10)$ & $-0.25 \quad(0.10)$ & $-0.61 \quad(0.09)$ & $-0.62(0.09)$ \\
\hline 2 & $-0.18 \quad(0.10)$ & $-0.33(0.10)$ & $-0.58 \quad(0.09)$ & $-0.68(0.09)$ \\
\hline 1 & $-0.18 \quad(0.10)$ & $-0.36(0.10)$ & $-0.49(0.09)$ & $-0.65(0.09)$ \\
\hline 0 & $-0.23 \quad(0.10)$ & $-0.38 \quad(0.10)$ & $-0.35(0.09)$ & $-0.55(0.09)$ \\
\hline-1 & $-0.17 \quad(0.10)$ & $-0.35 \quad(0.10)$ & $-0.17 \quad(0.09)$ & $-0.39(0.09)$ \\
\hline-2 & $-0.10 \quad(0.10)$ & $-0.31 \quad(0.10)$ & $-0.00(0.09)$ & $-0.23(0.09)$ \\
\hline-3 & $-0.03 \quad(0.10)$ & $-0.24 \quad(0.10)$ & $0.14 \quad(0.09)$ & $-0.07(0.09)$ \\
\hline \multirow[t]{2}{*}{-4} & $0.01 \quad(0.10)$ & $-0.14 \quad(0.10)$ & $0.26 \quad(0.09)$ & $0.08 \quad(0.09)$ \\
\hline & \multicolumn{3}{|c|}{ First Differences of Prices and Output } & \\
\hline 4 & $-0.08 \quad(0.10)$ & $-0.05 \quad(0.10)$ & $-0.20(0.09)$ & $-0.21(0.09)$ \\
\hline 3 & $-0.07 \quad(0.10)$ & $-0.16 \quad(0.10)$ & $-0.34(0.09)$ & $-0.28(0.09)$ \\
\hline 2 & $-0.14 \quad(0.10)$ & $-0.21 \quad(0.10)$ & $-0.31(0.09)$ & $-0.32(0.09)$ \\
\hline 1 & $0.01 \quad(0.10)$ & $-0.20 \quad(0.10)$ & $-0.20(0.09)$ & $-0.29(0.09)$ \\
\hline 0 & $-0.28 \quad(0.10)$ & $-0.20 \quad(0.10)$ & $-0.13(0.09)$ & $-0.23(0.09)$ \\
\hline-1 & $-0.05 \quad(0.10)$ & $-0.10 \quad(0.10)$ & $0.01 \quad(0.09)$ & $-0.04(0.09)$ \\
\hline-2 & $-0.03 \quad(0.10)$ & $-0.20 \quad(0.10)$ & $0.13(0.09)$ & $0.00(0.09)$ \\
\hline-3 & $0.03 \quad(0.10)$ & $-0.15 \quad(0.10)$ & $0.09(0.09)$ & $0.01(0.09)$ \\
\hline-4 & $-0.05 \quad(0.10)$ & $-0.01 \quad(0.10)$ & $0.15 \quad(0.09)$ & $0.15(0.09)$ \\
\hline
\end{tabular}

than those by other detrending methods, implying the negative association between inflation and economic growth. In Taiwan, however, correlations are negative for all the leads and insignificantly positive at most lags.

In sum, the implication from Table 3 is that, whichever method is used in detrending, the cross correlations of the cyclical components of prices and output are negative for all the cases for Korea and for most cases for Taiwan, although the significance of the relationship is different. ${ }^{4}$ The results do not change much regardless of which measure of prices, either the deflator or $\mathrm{CPI}$, is used. This indicates that there is strong evidence for the countercyclical price behavior in Korea and Taiwan as in the case for the industrialized countries documented in Chadha and Prasad (1994).

\section{Correlation Between Inflation and the Cyclical Component of O utput}

As discussed above, many conventional models of business cycles imply that the inflation rate, rather than the price level, is procyclical. Hence the correlations are calculated again between inflation and detrended output. The comparison of inflation versus the detrended price level is illustrated for the HP method in Figure 3. Figure 3a shows the clearly countercyclical nature of price and output reported in Table 3. Figure 3b shows the procyclical nature of inflation that is documented below.

Figure $3 \mathrm{~b}$ plots the inflation rate with the deviations of output from the HP trend. Table 4 presents correlations between inflation and various measures of the cyclical component of output similarly

\footnotetext{
${ }^{4}$ In Taiwan, detrending using a simple linear trend may not be appropriate, since all the other detrending methods give similar results.
} 


\section{Figure 3}

a. HP-Filtered Prices and Output: Korea

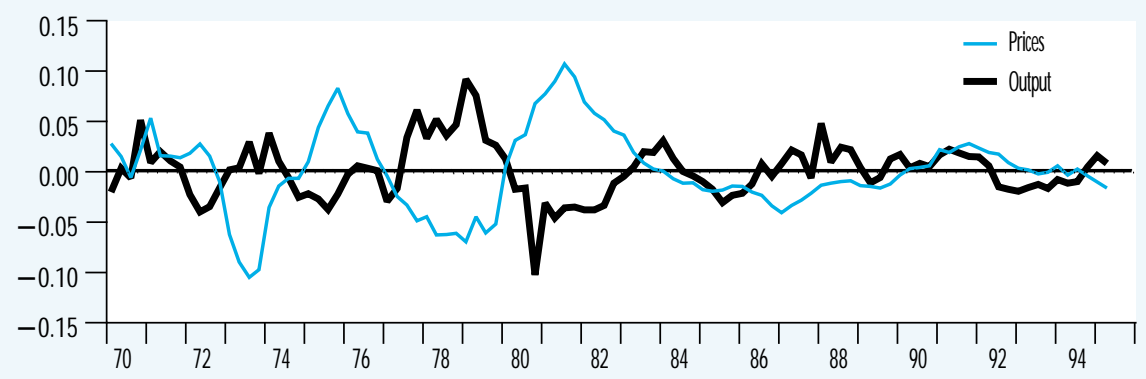

b. Inflation and HP-Filtered Output: Korea

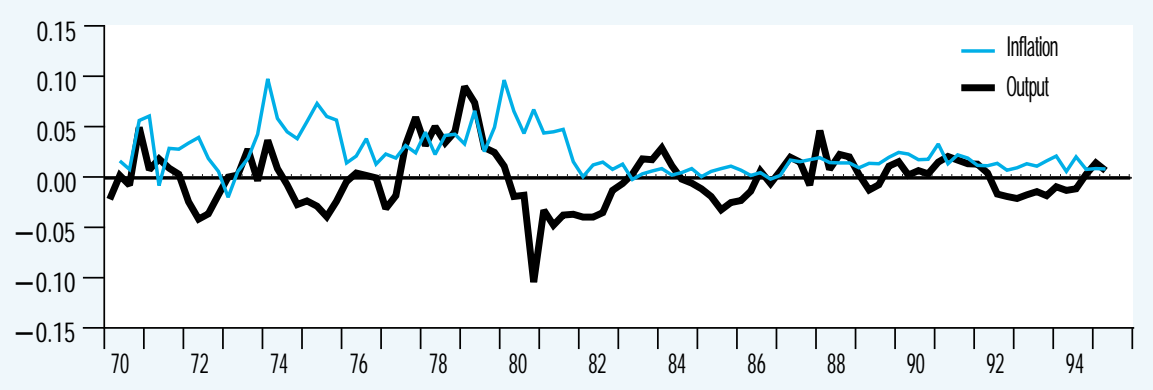

defined as in Table 3. The rate of inflation is measured as the first difference of the log of the price level. The remarkable features of Table 4 are that (1) the positive correlations between inflation and output are prevalent across all the detrending methods, contrary to the correlations between price level and output, which are negative in most cases, and (2) that the magnitudes of the correlations are larger in Taiwan than in Korea. The first panel shows that the correlations between inflation and output that have been detrended using a linear trend are all positive for Taiwan, regardless of price measures, and for Korea they are all positive when inflation is measured by the deflator. The second through fourth panels show that the correlations between inflation and output are generally positive for both countries, no matter which method is used to take this trend out of the data.

Finally, the correlations between inflation and cyclical output that have been detrended by the PAT technique are again basically positive for both countries, a result that is very similar to that shown in panels 2 and 3. The results in Table 4 indicate procyclical variations in inflation for most cases, in contrast to the case when price level is used. This finding is consistent with the findings for G-7 countries presented by Chadha and Prasad (1994).

Table 5 presents the results for the test of the possibilities of a change in correlation structure between prices or inflation and cyclical output before and after the identified break point by Zivot and Andrews' procedure (1992). Although output series in both Korea and Tai wan turn out to be difference-stationary statistically, both countries may have experienced a structural change. Hence the same analysis is done during the subsample period, before and after the break point. The break point used for each country is that for output from the Zivot and Andrews test (Table 1 ). Instead of reporting all the cross correlations, the correlation between cyclical prices and inflation and output, based on the HP filter and the growth cycle program, are presented. 


\section{Table 4}

\section{Cross Correlations of Inflation and Cyclical Components of Output}

\begin{tabular}{|c|c|c|c|c|}
\hline \multirow{2}{*}{$\frac{\text { Lead/ Lag }}{\text { (- denotes lag) }}$} & \multicolumn{2}{|c|}{ Korea } & \multicolumn{2}{|c|}{ Taiw an } \\
\hline & Deflator & $\underline{\mathrm{CPI}}$ & Deflator & $\underline{\mathrm{CPI}}$ \\
\hline & \multicolumn{3}{|c|}{ Inflation and Detrended Output (Linear Trend) } & \\
\hline 4 & $0.06(0.10)$ & $-0.11 \quad(0.10)$ & $0.16(0.09)$ & $0.07 \quad(0.09)$ \\
\hline 3 & $0.10(0.10)$ & $-0.09 \quad(0.10)$ & $0.22(0.09)$ & $0.12 \quad(0.09)$ \\
\hline 2 & $0.13(0.10)$ & $-0.02 \quad(0.10)$ & $0.31 \quad(0.09)$ & $0.20 \quad(0.09)$ \\
\hline 1 & $0.19 \quad(0.10)$ & $0.08 \quad(0.10)$ & $0.40 \quad(0.09)$ & $0.27 \quad(0.09)$ \\
\hline 0 & $0.19(0.10)$ & $0.16(0.10)$ & $0.46 \quad(0.09)$ & $0.36 \quad(0.09)$ \\
\hline-1 & $0.31 \quad(0.10)$ & $0.26 \quad(0.10)$ & $0.49 \quad(0.09)$ & $0.42 \quad(0.09)$ \\
\hline-2 & $0.34 \quad(0.10)$ & $0.30 \quad(0.10)$ & $0.47 \quad(0.09)$ & $0.43 \quad(0.09)$ \\
\hline-3 & $0.35 \quad(0.10)$ & $0.40 \quad(0.10)$ & $0.43 \quad(0.09)$ & $0.42 \quad(0.09)$ \\
\hline-4 & $0.34 \quad(0.10)$ & $0.47 \quad(0.10)$ & $0.40(0.09)$ & $0.42 \quad(0.09)$ \\
\hline \multicolumn{5}{|c|}{ Inflation and Detrended Output (Segmented Trend) } \\
\hline 4 & $-0.00 \quad(0.10)$ & $-0.09 \quad(0.10)$ & $-0.20 \quad(0.09)$ & $-0.30(0.09)$ \\
\hline 3 & $-0.03 \quad(0.10)$ & $-0.08 \quad(0.10)$ & $-0.09 \quad(0.09)$ & $-0.19(0.09)$ \\
\hline 2 & $0.03 \quad(0.10)$ & $-0.00 \quad(0.10)$ & $0.08 \quad(0.09)$ & $-0.05 \quad(0.09)$ \\
\hline 1 & $0.14 \quad(0.10)$ & $0.12(0.10)$ & $0.25 \quad(0.09)$ & $0.11 \quad(0.09)$ \\
\hline 0 & $0.10(0.10)$ & $0.18 \quad(0.10)$ & $0.36(0.09)$ & $0.26 \quad(0.09)$ \\
\hline-1 & $0.20(0.10)$ & $0.31 \quad(0.10)$ & $0.43 \quad(0.09)$ & $0.38 \quad(0.09)$ \\
\hline-2 & $0.23(0.10)$ & $0.33(0.10)$ & $0.44 \quad(0.09)$ & $0.41 \quad(0.09)$ \\
\hline-3 & $0.20(0.10)$ & $0.33(0.10)$ & $0.39 \quad(0.09)$ & $0.41 \quad(0.09)$ \\
\hline-4 & $0.14 \quad(0.10)$ & $0.36 \quad(0.10)$ & $0.35 \quad(0.09)$ & $0.41 \quad(0.09)$ \\
\hline \multicolumn{5}{|c|}{ Inflation and Detrended Output (HP Filter) } \\
\hline 4 & $-0.08 \quad(0.10)$ & $-0.25 \quad(0.10)$ & $-0.26(0.09)$ & $-0.37 \quad(0.09)$ \\
\hline 3 & $-0.06 \quad(0.10)$ & $-0.27 \quad(0.10)$ & $-0.15 \quad(0.09)$ & $-0.26(0.09)$ \\
\hline 2 & $-0.04 \quad(0.10)$ & $-0.20 \quad(0.10)$ & $0.06 \quad(0.09)$ & $-0.09 \quad(0.09)$ \\
\hline 1 & $0.04 \quad(0.10)$ & $-0.08 \quad(0.10)$ & $0.25 \quad(0.09)$ & $0.09 \quad(0.09)$ \\
\hline 0 & $-0.01 \quad(0.10)$ & $0.03 \quad(0.10)$ & $0.37 \quad(0.09)$ & $0.27 \quad(0.09)$ \\
\hline-1 & $0.18(0.10)$ & $0.14(0.10)$ & $0.45(0.09)$ & $0.40 \quad(0.09)$ \\
\hline-2 & $0.21 \quad(0.10)$ & $0.18(0.10)$ & $0.45 \quad(0.09)$ & $0.42 \quad(0.09)$ \\
\hline-3 & $0.21(0.10)$ & $0.31(0.10)$ & $0.37(0.09)$ & $0.41 \quad(0.09)$ \\
\hline-4 & $0.17(0.10)$ & $0.41 \quad(0.10)$ & $0.32(0.09)$ & $0.41 \quad(0.09)$ \\
\hline \multicolumn{5}{|c|}{ Inflation and Detrended Output (PAT) } \\
\hline 4 & $-0.04 \quad(0.10)$ & $-0.25(0.10)$ & $-0.16(0.09)$ & $-0.29(0.09)$ \\
\hline 3 & $-0.01 \quad(0.10)$ & $-0.25 \quad(0.10)$ & $-0.05(0.09)$ & $-0.18 \quad(0.09)$ \\
\hline 2 & $0.01 \quad(0.10)$ & $-0.17(0.10)$ & $0.14(0.09)$ & $-0.02(0.09)$ \\
\hline 1 & $0.10(0.10)$ & $-0.05 \quad(0.10)$ & $0.33(0.09)$ & $0.16 \quad(0.09)$ \\
\hline 0 & $0.06(0.10)$ & $0.06(0.10)$ & $0.45 \quad(0.09)$ & $0.32 \quad(0.09)$ \\
\hline-1 & $0.24 \quad(0.10)$ & $0.17(0.10)$ & $0.53(0.09)$ & $0.46 \quad(0.09)$ \\
\hline-2 & $0.27 \quad(0.10)$ & $0.20(0.10)$ & $0.52(0.09)$ & $0.47 \quad(0.09)$ \\
\hline-3 & $0.26(0.10)$ & $0.32(0.10)$ & $0.45(0.09)$ & $0.46 \quad(0.09)$ \\
\hline-4 & $0.23(0.10)$ & $0.42 \quad(0.10)$ & $0.40 \quad(0.09)$ & $0.46 \quad(0.09)$ \\
\hline
\end{tabular}

Note: Standard errors are provided in parentheses.

\footnotetext{
${ }^{5}$ The test for statistical significance is based on the Wald test described in Ostle (1963), pages 225-227. The Wald statistic is distributed as a Chisquare with one degree of freedom. The value for a ten percent critical region is 2.71 .
} 


\section{Table 5}

\section{Cross Correlations of Prices and Output: Pre- and Post- Break}

Lead/ Lag

Korea

Taiw an

\begin{tabular}{|c|c|c|c|c|c|c|c|c|c|c|c|c|}
\hline \multirow[t]{2}{*}{ (- means lag) } & \multicolumn{3}{|c|}{ Deflator } & \multicolumn{3}{|c|}{ CPI } & \multicolumn{3}{|c|}{ Deflator } & \multicolumn{3}{|c|}{ CPI } \\
\hline & $\begin{array}{c}\text { Full } \\
\text { Sample }\end{array}$ & $\begin{array}{l}\text { Pre- } \\
\text { Break }\end{array}$ & $\begin{array}{l}\text { Post- } \\
\text { Break }\end{array}$ & $\begin{array}{c}\text { Full } \\
\text { Sample }\end{array}$ & $\begin{array}{l}\text { Pre- } \\
\text { Break }\end{array}$ & $\begin{array}{l}\text { Post- } \\
\text { Break }\end{array}$ & $\begin{array}{l}\text { Full } \\
\text { ample }\end{array}$ & $\begin{array}{l}\text { Pre- } \\
\text { Break }\end{array}$ & $\begin{array}{l}\text { Post- } \\
\text { Break }\end{array}$ & $\begin{array}{c}\text { Full } \\
\text { Sample }\end{array}$ & $\begin{array}{l}\text { Pre- } \\
\text { Break }\end{array}$ & $\begin{array}{l}\text { Post- } \\
\text { Break }\end{array}$ \\
\hline \multicolumn{13}{|c|}{ Detrended Prices and Output (HP Filter for Both) } \\
\hline 4 & -0.29 & -0.18 & -0.36 & -0.26 & -0.23 & -0.19 & -0.68 & -0.73 & -0.49 & -0.59 & -0.57 & -0.60 \\
\hline 3 & -0.32 & -0.12 & -0.44 & -0.39 & -0.33 & -0.33 & -0.76 & -0.85 & -0.48 & -0.73 & -0.77 & -0.59 \\
\hline 2 & -0.39 & -0.21 & -0.50 & -0.51 & -0.47 & -0.45 & -0.74 & -0.83 & -0.48 & -0.79 & -0.86 & -0.58 \\
\hline 1 & -0.40 & -0.25 & -0.49 & -0.57 & -0.56 & -0.52 & -0.63 & -0.70 & -0.44 & -0.75 & -0.83 & -0.54 \\
\hline 0 & -0.47 & -0.37 & -0.55 & -0.58 & -0.55 & -0.59 & -0.47 & -0.50 & -0.38 & -0.63 & -0.69 & -0.49 \\
\hline-1 & -0.37 & -0.25 & -0.45 & -0.54 & -0.43 & -0.54 & -0.27 & -0.26 & -0.30 & -0.45 & -0.46 & -0.41 \\
\hline-2 & -0.26 & -0.11 & -0.38 & -0.48 & -0.30 & -0.46 & -0.08 & -0.05 & -0.21 & -0.26 & -0.26 & -0.31 \\
\hline-3 & -0.15 & 0.04 & -0.30 & -0.37 & -0.17 & -0.40 & -0.07 & 0.13 & -0.14 & -0.09 & -0.06 & -0.19 \\
\hline-4 & -0.07 & 0.05 & -0.22 & -0.21 & -0.05 & -0.30 & 0.20 & 0.27 & -0.06 & 0.09 & 0.13 & -0.07 \\
\hline \multicolumn{13}{|c|}{ Detrended Prices and Output (PAT for Both) } \\
\hline 4 & 0.14 & -0.10 & -0.26 & -0.17 & -0.23 & -0.08 & -0.55 & -0.74 & -0.34 & -0.51 & -0.55 & -0.51 \\
\hline 3 & -0.13 & -0.01 & -0.32 & -0.25 & -0.28 & -0.17 & -0.61 & -0.86 & -0.30 & -0.62 & -0.72 & -0.49 \\
\hline 2 & -0.18 & -0.09 & -0.35 & -0.33 & -0.41 & 0.24 & -0.58 & -0.85 & -0.26 & -0.68 & -0.81 & -0.46 \\
\hline 1 & -0.18 & -0.13 & -0.33 & -0.36 & -0.47 & -0.28 & -0.49 & -0.72 & -0.21 & -0.65 & -0.80 & -0.39 \\
\hline 0 & -0.23 & -0.25 & -0.33 & -0.38 & -0.47 & -0.32 & -0.35 & -0.53 & -0.14 & -0.55 & -0.69 & -0.32 \\
\hline-1 & -0.17 & -0.15 & -0.28 & -0.35 & -0.34 & -0.32 & 0.17 & -0.30 & -0.05 & -0.39 & -0.50 & -0.21 \\
\hline-2 & -0.10 & -0.03 & -0.23 & -0.31 & -0.22 & -0.29 & 0 & -0.08 & 0.04 & -0.23 & -0.32 & -0.09 \\
\hline-3 & -0.03 & 0.09 & -0.19 & -0.24 & -0.10 & -0.28 & 0.14 & 0.09 & 0.14 & -0.07 & -0.15 & 0.05 \\
\hline-4 & 0.01 & 0.10 & -0.17 & -0.14 & 0.03 & -0.26 & 0.26 & 0.22 & 0.24 & 0.08 & 0.01 & 0.19 \\
\hline \multicolumn{13}{|c|}{ Inflation and Detrended Output (HP Filter) } \\
\hline 4 & -0.08 & -0.15 & -0.33 & -0.25 & -0.21 & -0.51 & -0.26 & -0.44 & 0.15 & -0.37 & -0.54 & 0.10 \\
\hline 3 & -0.06 & -0.01 & -0.42 & -0.27 & -0.20 & -0.59 & -0.15 & -0.28 & 0.18 & -0.26 & -0.39 & 0.17 \\
\hline 2 & -0.04 & -0.08 & -0.32 & -0.20 & -0.21 & -0.44 & 0.06 & 0.02 & 0.20 & -0.09 & -0.19 & 0.23 \\
\hline 1 & 0.04 & -0.07 & -0.14 & -0.08 & -0.11 & -0.29 & 0.25 & 0.26 & 0.29 & 0.09 & 0.03 & 0.33 \\
\hline 0 & -0.01 & -0.12 & -0.16 & 0.03 & 0.10 & -0.21 & 0.37 & 0.40 & 0.35 & 0.27 & 0.25 & 0.36 \\
\hline-1 & 0.18 & 0.09 & 0.03 & 0.14 & 0.21 & -0.04 & 0.45 & 0.50 & 38 & 0.40 & 0.42 & 0.41 \\
\hline-2 & 0.21 & 0.10 & 0.01 & 0.18 & 0.17 & 04 & 0.45 & 0.47 & .41 & 0.42 & 0.41 & 0.48 \\
\hline-3 & 0.21 & 0.13 & 0.06 & 0.31 & 0.20 & 0.04 & 0.37 & 0.39 & 0.39 & 0.41 & 0.40 & 0.52 \\
\hline-4 & 0.17 & -0.06 & 0.09 & 0.41 & 0.21 & 0.15 & 0.32 & 0.32 & 0.40 & 0.41 & 0.38 & 0.54 \\
\hline \multicolumn{13}{|c|}{ Inflation and Detrended Output (PAT) } \\
\hline 4 & -0.04 & -0.16 & 0.32 & -0.25 & -0.23 & -0.51 & -0.16 & -0.40 & 0.28 & -0.29 & -0.50 & 0.22 \\
\hline 3 & -0.02 & -0.02 & -0.40 & -0.25 & -0.22 & -0.58 & -0.05 & -0.24 & 0.32 & -0.18 & -0.36 & 0.30 \\
\hline 2 & 0.01 & -0.09 & -0.31 & -0.17 & -0.22 & -0.45 & 0.14 & 0.06 & 0.36 & -0.02 & -0.16 & 0.37 \\
\hline 1 & 0.10 & -0.05 & -0.14 & -0.05 & -0.09 & -0.30 & 0.33 & 0.31 & 0.45 & .16 & 0.07 & 0.47 \\
\hline 0 & 0.06 & -0.09 & -0.17 & 0.06 & 0.13 & -0.24 & 0.43 & 0.45 & 0.51 & 0.32 & 0.29 & 0.50 \\
\hline-1 & 0.24 & 0.14 & 0 & 0.17 & 0.25 & -0.08 & 0.53 & 0.56 & 0.56 & 0.46 & 0.46 & 0.56 \\
\hline-2 & 0.27 & 0.15 & -0.02 & 0.20 & 0.21 & -0.02 & 0.52 & 0.52 & 0.59 & 0.47 & 0.45 & 0.61 \\
\hline-3 & 0.26 & 0.18 & 0.02 & 0.32 & 0.25 & 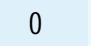 & 0.45 & 0.43 & 0.56 & 0.46 & 0.44 & 0.64 \\
\hline-4 & 0.23 & 0.03 & 0.05 & 0.42 & 0.26 & 0.10 & 0.40 & 0.37 & 0.55 & 0.46 & 0.42 & 0.64 \\
\hline
\end{tabular}

Note: Shaded cells indicate instances in which the difference is significant at the $10 \%$ level. 
The differences between the correlations across the assigned break point that are significant at a 10 percent level are shaded in Table $5 .{ }^{5}$ In the case of Taiwan, 33 of 72 reported correlations are significantly different. This result is consistent with the findings of Backus and Kehoe (1992), who report that the output-price correlations vary across countries and time periods. It is also consistent with Gavin and Kydland (1995), who find a significant break in the covariance structure of output and prices for the United States, which they attribute to a policy change in 1979. In the case of Korea, only five of the seventy-two differences are significant at the 10 percent level. The lower rejection rate for Korea is associated with both fewer large differences and the smaller sample size used to construct the test statistics.

\section{CONCLUSION}

The main finding of this paper is that, in Korea and Taiwan, the detrended price level is negatively correlated with cyclical output, while inflation is positively correlated with the cyclical component of output. The results generally hold, whether price is measured by the deflator or by the consumer price index, for a number of filtering procedures and for subsamples before and after the estimated dates of structural breaks in output. This result confirms the findings of Chadha and Prasad (1994) in G-7 countries, that the price level is countercyclical, while inflation is procyclical.

The results do not seem to suggest any decisive conclusions regarding the appropriate model for the business cycle. While the countercyclical behavior of the price level is consistent with the predictions the supply-determined models of the business cycle, the procyclical behavior of the inflation rate is consistent with the predictions of conventional demand-determined models of the business cycle. This finding is consistent with the recent contradictory findings concerning the sources of economic fluctuations in Korea; Yoo (1992) finds that supply shocks are a dominant factor in output fluctuations, while Jun (1992) finds that aggregate demand shocks are important. These two researchers both used a slightly different structural VAR model of the Blanchard and Quah (1989) type.

Further research is needed to reconcile these contradictory findings. For instance, in cases where covariance structure is stationary, it may be useful to apply a coherence measure in spectral analysis, which represents the proportion of the variance of either series that can be explained by the other, frequency by frequency. In cases where the correlation structure between output and prices has changed, it is important to use theories for a better understanding of why the changes have occurred.

\section{REFEREN CES}

Alba, Joseph P., and Papell, David H. "Trend Breaks and the Unit Root Hypothesis for Newly Industrializing and Newly Exporting Countries," Review of Intemational Economics (October 1995), pp. 264- 74.

Backus, David K., and Patrick J. Kehoe. "International Evidence of the Historical Properties of Business Cycles," The American Economic Review (September 1992), pp. 864-88.

Banerjee, Anindya, Robin L. Lumsdaine, and James H. Stock. "Recursive and Sequential Tests of the Unit Root and Trend-Break Hypotheses: Theory and International Evidence," Journal of Business and Economic Statistics (July 1992), pp. 271-87.

Beveridge, Stephen, and Charles R. Nelson. "A New Approach to Decomposition of Economic Time Series into Permanent and Transitory Components with Particular Attention to the Measurement of the 'Business Cycle,'" Journal of Monetary Economics (March 1981), pp. 151- 74 .

Blanchard, Olivier J ean, and Danny Quah. "The Dynamic Effects of Aggregate Demand and Supply Disturbances," The American Economic Review (September 1989), pp. 655- 73.

Bry, Gerhard, and Charlotte Boschan. Cyclical Analysis of Time Series: Selected Procedures and Computer Programs, National Bureau of Economic Research, 1971.

Chadha, Bankim, and Eswar Prasad. "Interpreting the Cyclical Behavior of Prices," International Monetary Fund Staff Papers (June 1993), pp. 266- 98.

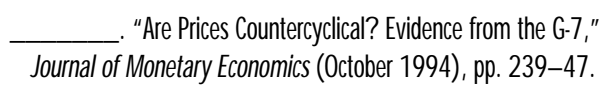

Christiano, Lawrence ). "Searching for a Break in GNP," Journal of Business and Economic Statistics (July 1992), pp. 237- 50. 


\section{REVIEW}

September/ October 1996

Cogley, Timothy, and James M. Nason. "Effects of the Hodrick-Prescott Filter on Trend and Difference Stationary Time Series: Implications for Business Cycle Research," Joumal of Economic Dynamics and Control, (Jan.Feb. 1995), pp. 253- 78.

Cooley, Thomas F., and Lee E. Ohanian. "The Cyclical Behavior of Prices," Journal of Monetary Economics (August 1991), pp. 25- 60.

Gavin, William T., and Finn E. Kydland. "Endogenous Money Supply and the Business Cycle," Working Paper 95-010, Federal Reserve Bank of St. Louis, 1995.

Gregory, Allan W. and Gregor W. Smith. "Business Cycle Theory and Econometrics," The Economic Joumal (November 1995), pp. 1597-1608.

Hall, Thomas E. "Price Cyclicality in the Natural Rate-Nominal Demand Shock Model," Journal of Macroeconomics (Spring 1995), pp. 257- 72 .

Harvey, A.H. and A. Jaeger. "Detrending, Stylized Facts and the Business Cycle," Joumal of Applied Econometrics (July-Sept. 1993), pp. 231- 47.

Hodrick, Robert J. and Edward C. Prescott. "Post-War U.S. Business Cycles: An Empirical Investigation," Discussion Paper 451, Northwestem University, Revised May 1981.

Judd, John P. and Bharat Trehan. "The Cyclical Behavior of Prices: Interpreting the Evidence," Joumal of Money, Credit, and Banking (August 1995), pp. 789- 97.

Jun, S. "Money, Prices, Nominal Wages: Long-Run and Short-Run Dynamics," Korea Development Institute Studies (Spring 1992), pp. 37-60.

King, Robert G. and Sergio T. Rebelo. "Low Frequency Filtering and Real Business Cycles," Journal of Economic Dynamics and Control (Jan.Mar. 1993), pp. 207- 31.

Klein, Philip A. and Geoffrey Hoyt Moore. "Monitoring Growth Cycles in Market-Oriented Countries: Developing and Using International Economic Indicators," Ballinger, 1985

Kydland, Finn E. and Edward C. Prescott. "Time to Build and Aggregate Fluctuations," Econometrica (November 1982), pp. 1345- 70.

\section{. . "Business Cycles: Real Facts and a Monetary Myth," Quarterly Review, Federal Reserve Bank of Minneapolis (Spring 1990), pp. 3- 18.}

Nelson, Charles R. and Charles I. Plosser. "Trends and Random Walks in Macroeconomic Time Series: Some Evidence and Implications," Journal of Monetary Economics (September 1982), pp. 139- 62.

Ostle, Bernard. Statistics in Research. Ames, lowa: Iowa University Press, 1963.

Perron, Pierre. "The Great Crash, the Oil Price Shock, and the Unit Root Hypothesis," Econometrica (November 1989), pp. 1361- 401.
Serletis, Apostolos. "International Evidence on Breaking Trend Functions in Macroeconomic Variables," Applied Economics (February 1994), pp. $175-79$.

Smith, R. Todd. "The Cyclical Behavior of Prices," Joumal of Money, Credit, and Banking (November 1992), pp. 413- 30.

Yoo, B. Sam. "Effects of Demand and Supply Shocks on the Korean Economy," Monetary and Financial Studies Working Paper \#52, Bank of Korea Institute for Monetary and Economic Research, 1992.

Zarnowitz, V. "Business Cycles: Theory, History, Indicators, and Forecasting," The University of Chicago Press, 1992.

Zivot, Eric, and Donald W. K. Andrews. "Further Evidence on the Great Crash, the Oil Price Shock and the Unit Root Hypothesis," Journal of Business and Economic Statistics (July 1992), pp. 251- 70. 